Article

\title{
Plasmin Regulation through Allosteric, Sulfated, Small Molecules
}

\author{
Rami A. Al-Horani $^{\dagger}{ }^{\dagger}$, Rajesh Karuturi $^{\dagger}$, Domonique T. White and Umesh R. Desai \\ Department of Medicinal Chemistry and Institute for Structural Biology and Drug Discovery, \\ Virginia Commonwealth University, Richmond, VA 23219, USA; E-Mails: rkaruturi@vcu.edu (R.K.); \\ d.t.white17696@spartans.nsu.edu (D.T.W.); urdesai@vcu.edu (U.R.D.)
}

$\dagger$ These authors contributed equally to this work.

* Author to whom correspondence should be addressed; E-Mail: alhoranir@vcu.edu; Tel.: +1-804-503-2258; Fax: +1-804-827-3664.

Academic Editor: Vito Ferro

Received: 30 October 2014 / Accepted: 26 December 2014 / Published: 5 January 2015

\begin{abstract}
Plasmin, a key serine protease, plays a major role in clot lysis and extracellular matrix remodeling. Heparin, a natural polydisperse sulfated glycosaminoglycan, is known to allosterically modulate plasmin activity. No small allosteric inhibitor of plasmin has been discovered to date. We screened an in-house library of 55 sulfated, small glycosaminoglycan mimetics based on nine distinct scaffolds and varying number and positions of sulfate groups to discover several promising hits. Of these, a pentasulfated flavonoid-quinazolinone dimer 32 was found to be the most potent sulfated small inhibitor of plasmin $\left(I_{50}=45 \mu \mathrm{M}\right.$, efficacy $=100 \%$ ). Michaelis-Menten kinetic studies revealed an allosteric inhibition of plasmin by these inhibitors. Studies also indicated that the most potent inhibitors are selective for plasmin over thrombin and factor $\mathrm{Xa}$, two serine proteases in coagulation cascade. Interestingly, different inhibitors exhibited different levels of efficacy (40\%-100\%), an observation alluding to the unique advantage offered by an allosteric process. Overall, our work presents the first small, synthetic allosteric plasmin inhibitors for further rational design.
\end{abstract}

Keywords: allosteric inhibitors; library screening; plasmin; sulfated glycosaminoglycan mimetics 


\section{Introduction}

Plasmin, a trypsin-like serine protease, promotes intravascular dissolution of fibrin clots $[1,2]$. Plasmin inhibitors are clinically used as antifibrinolytics so as to reduce excessive blood loss during major surgeries such as cardiac surgery with cardiopulmonary bypass [3,4]. Plasmin inhibitors are also used to manage cases of hemophilia, menorrhagia, von Willebrand syndrome, disseminated intravascular coagulation, and thrombolytics-induced bleeding. Plasmin can also be produced at the cell surface as to contribute to the degradation of extracellular matrix resulting in modulation of tissue remodeling, cell invasion, and/or metastasis and chemotaxis. This implies that inhibitors of plasmin could potentially benefit many other pathologies too including angioedema, chronic inflammatory responses, and lymphoid malignancies [1,2].

Nevertheless, only two indirect inhibitors of plasmin are approved for use as antifibrinolytics in the clinic today. Tranexamic acid and $\varepsilon$-aminocaproic acid, two analogs of lysine, bind to the lysine-binding sites in the kringle domains of plasminogen resulting in attenuation of plasmin formation [1]. Both lysine analogs have no direct inhibitory effect on active plasmin leading to their limited efficacy. A direct plasmin inhibitor, which is approved for use in only few countries, is aprotinin. Although useful, aprotinin, a Kunitz-type plasmin inhibitor, was withdrawn from the clinic in the U.S. due to its high risk of mortality and morbidity [5,6]. The two lysine analogs also suffer from significant adverse effects arising from their effects on the central GABA receptor, which provokes convulsive seizures [7]. In particular, the low efficacy of tranexamic acid necessitates administration of high doses (1 to $20 \mathrm{~g}$ ), which invokes postoperative convulsive seizures, chest tube drainage, and renal dysfunction [8]. Thus, discovering more potent and safer plasmin inhibitors is important and urgent.

Several small molecules are being developed as inhibitors of human plasmin [1]. Each of these is an active site inhibitor, which is typically easier to discover considering the availability of known substrate sequence specificity. Yet, ensuring selective inhibition of plasmin by active site inhibitors is challenging because of the substantial homology to other trypsin-like serine proteases including thrombin, factor Xa, factor XIa, kallikrein, and activated protein C [9]. We reasoned that discovering allosteric inhibitors of plasmin would be advantageous because of the possibility of higher specificity and regulation characteristics.

To realize this, we studied an in-house library of 55 sulfated small molecules (Figure 1) considering their similarity to sulfated glycosaminoglycans (GAGs), which had earlier been known to allosterically inhibit plasmin [1]. The focused library was synthesized and screened against human Lys-plasmin using a chromogenic substrate hydrolysis assay to identify several molecules with reasonable activity. In particular, inhibitor 32 inhibited the proteolytic activity of plasmin with an $I C_{50}$ of $45 \mu \mathrm{M}$ and efficacy of $100 \%$. Michaelis-Menten kinetic studies revealed that molecule 32 is an allosteric inhibitor. Interestingly, several inhibitors displayed different levels of efficacy (40\%-100\%), an observation alluding to the possibility of regulating plasmin activity. Molecule $\mathbf{3 2}$ is the first homogeneous and non-polymeric allosteric inhibitor of plasmin and is expected to serve as a unique platform to guide future efforts to design highly potent and selective regulators of plasmin. 


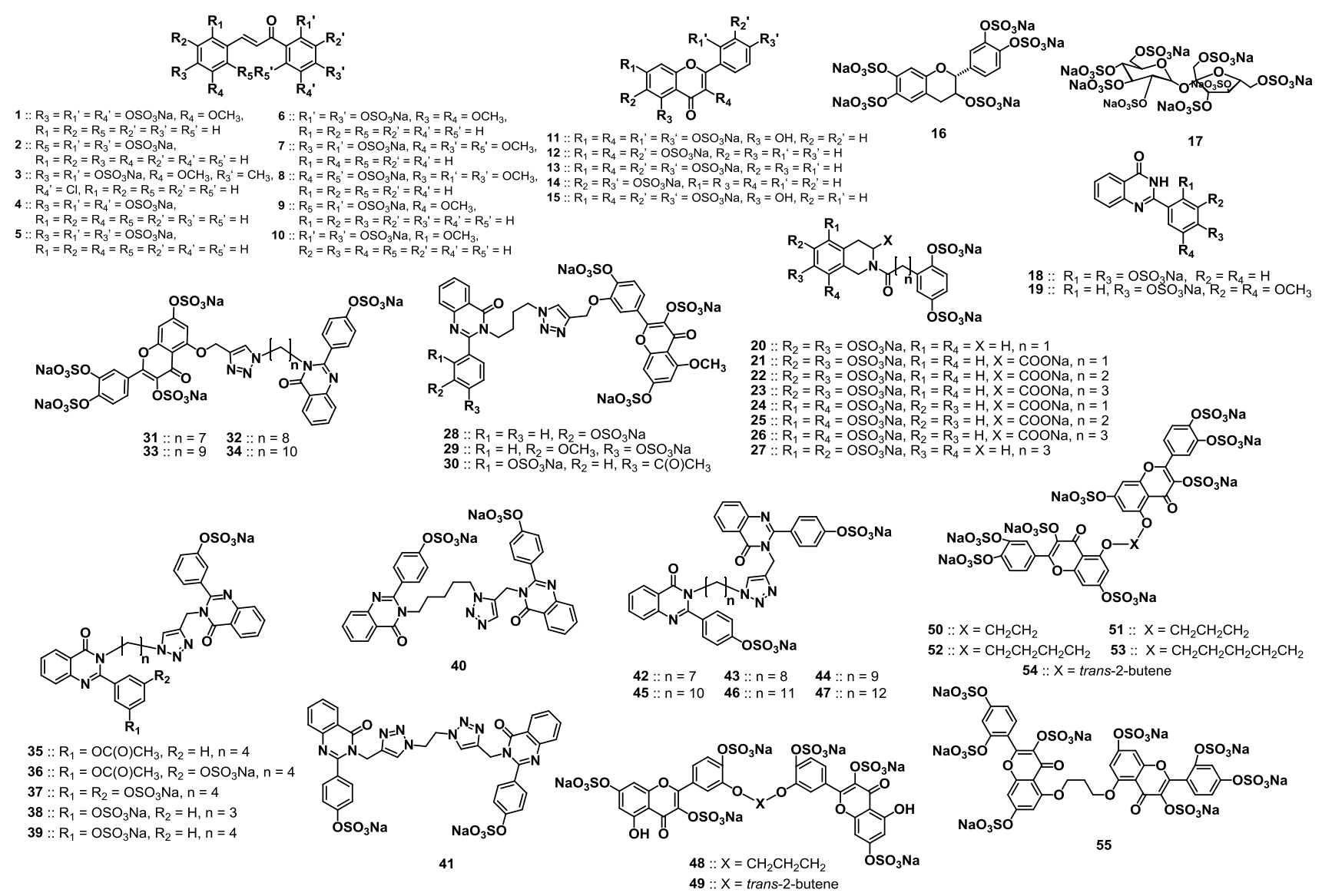

Figure 1. Structures of the sulfated small molecules screened for human plasmin inhibition. The library includes 55 molecules belonging to diverse chemical classes of chalcones (compounds 1-10), flavonoids (11-16), sucrose octasulfate (17), quinazolinones (18 and 19), tetrahydroisoquinolines (20-27), flavonoid-quinazolinone heterodimers (28-34), bis-quinazolinone homodimers (35-47), and bis-flavonoid homodimers (48-55). The sulfated molecules also differed in the number of sulfate groups (1-8/molecule) as well as their spatial orientation.

\section{Results and Discussion}

\subsection{Rationale for Screening a Focused Library of Sulfated Small Molecules against Human Plasmin}

Many different approaches have been utilized to discover and/or rationally design inhibitors of plasmin. These approaches include substrate-based design of linear and cyclic peptidomimetics [10-14], mutagenesis of key residues to engineer Kunitz- and Kazal-type protein/peptide inhibitors [15-17], covalent inhibition through a reactive nitrile or aldehyde warhead [18,19], and structure-based computational inhibitor design [20,21]. Each of these approaches typically targets the enzyme's active site. Yet, the literature supports the idea of allosteric modulation of plasmin's catalytic activity. For example, heparin is known to bind directly to plasmin with a $K_{D}$ of $10 \mathrm{nM}$ and induce a conformational change in its active site by interacting with an allosteric site [22-25]. Likewise, $N$-oleoyl heparin was also found to inhibit plasmin $\left(I C_{50}=16 \mathrm{nM}\right)$ and Lineweaver-Burk analysis indicated noncompetitive inhibition mechanism [26]. In addition, another group of highly sulfated GAG mimetics, e.g., sulfated 
low molecular weight lignins (CDSO3 IC $C_{50} 0.24 \mu \mathrm{M}$ ) [27], chemically modified dextran sulfate derivatives (RG1192 IC50 $2 \mathrm{nM}$ ) [28], and sulfated polyvinylalcohol-acrylate copolymers (IC50 $100 \mathrm{nM}$ ) [29] have also been reported to inhibit plasmin.

Sulfated GAGs or sulfated polymeric GAG mimetics are highly heterogeneous polymers, which limits their further development as drugs. We reasoned that small, synthetic, homogenous, non-saccharide GAG mimetics (NSGMs) may offer an avenue for discovering novel plasmin inhibitors. In fact, Desai and co-workers have developed a sizeable number of NSGMs based on various scaffolds including sulfated flavonoids [30-33], sulfated benzofurans [34,35], sulfated tetrahydroisoquinolines [36], sulfated quinazolinones [37] and sulfated galloyl glucopyranosides [38,39] as modulators of a range of coagulation proteins. The NSGMs resemble sulfated GAGs in the form of presenting one or more sulfate groups to interact with GAG-binding domains on targeted proteins. Specificity of recognition arises from the three-dimensional orientation of key sulfate group(s), which depends on the type of non-saccharide scaffold. Considering that plasmin is known to possess a heparin-binding site, we predicted that one or more NSGM of the many synthesized in our focused library would inhibit plasmin in an allosteric manner.

\subsection{Chemical Synthesis of the Library of NSGMS}

We studied a library of 55 NSGMs representing nine distinct chemical classes of monomeric and dimeric scaffolds (Figure 1). The monomeric scaffolds included chalcones (compounds 1-10), flavonoids (11-16) [30-32], sucrose octasulfate (17) [40], quinazolinones (18 and 19) [37], and tetrahydro-isoquinolines (20-27) [36], whereas the dimeric scaffolds comprised flavonoid-quinazolinone heterodimers (28-34) [37], bis-quinazolinones homodimers (35-47) [37], and bis-flavonoid homodimers (48-55). In addition to the inherent diversity of the scaffolds in this library, NSGMs also differed in the number ( 1 to 8 ) and orientation of the sulfate groups. NSGMs 11-30, and 35-41 were synthesized as reported earlier [30-37].

New NSGMs synthesized for the first time included 10 sulfated chalcones (1-10), six sulfated bis-quinazolinones homodimers (42-47), four sulfated flavonoid-quinazolinone heterodimers (31-34), and eight sulfated bis-flavonoid homodimers (48-55). The synthesis of the new NSGMs is described in detail in Supplementary Information (Schemes S1-S6). Briefly, the synthesis of these NSGMs was achieved in 4 to 8 steps using traditional protection-deprotection chemistry following construction of the base scaffold with appropriate substitution pattern. The final step for the generation of each NSGM was chemical sulfation using trimethylamine-sulfur trioxide at elevated temperature, as described in our studies earlier [30-42]. For example, the synthesis of two promising plasmin inhibitors (Scheme 1) involved exploitation of the intramolecularly hydrogen bonded 5-OH group of quercetin $\mathbf{6 0}$ to selectively introduce a reactive handle (propargyl group in $\mathbf{6 3}$ or in situ alkyl bromide) that can be coupled with either an alkyl azide containing quinazolinone unit 32a or MOM-protected quercetin 61 to eventually give inhibitors 32 and 52, respectively. Overall, the new NSGMs were obtained in high yields (75\%-90\%) and their structural identity was confirmed using a combination of ${ }^{1} \mathrm{H}-$ and ${ }^{13} \mathrm{C}-\mathrm{NMR}$ spectroscopy and UPLC-MS (See Supplementary Information). 
A)

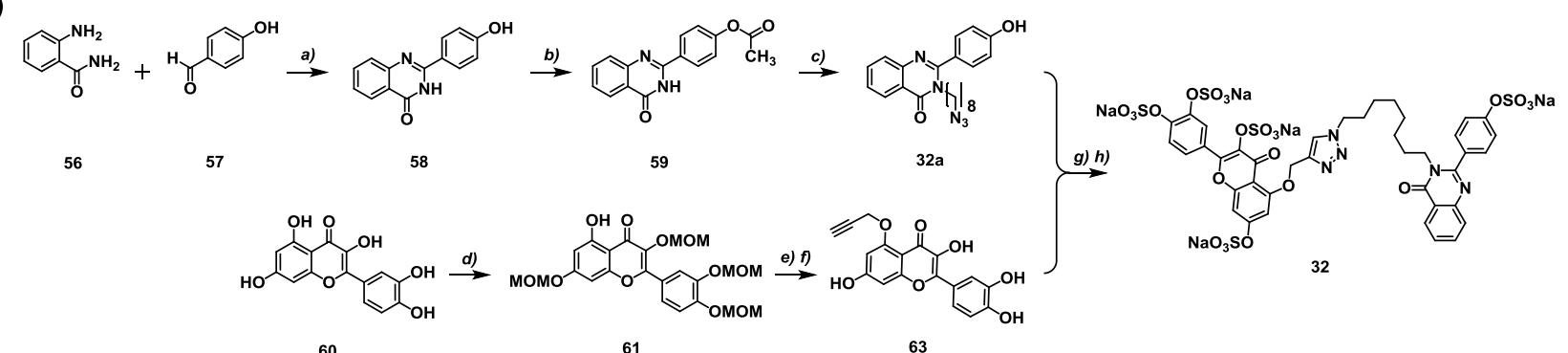

B)

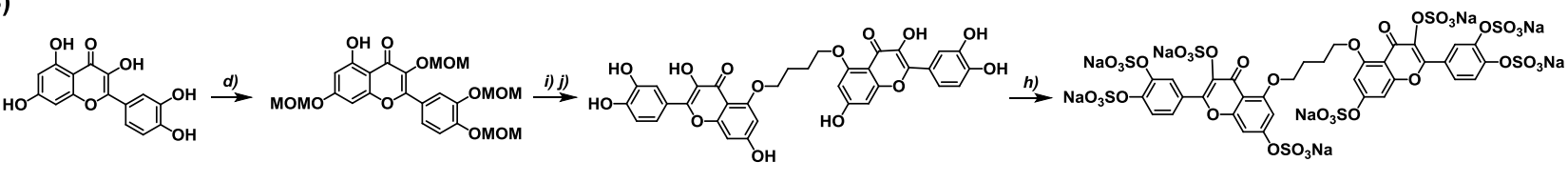

60

61

$52 a$

52

Scheme 1. Synthesis of inhibitors 32 (A) and 52 (B). a) NaHSO3, DMA, reflux/overnight, 65\%-80\%; b) $\mathrm{Ac}_{2} \mathrm{O}$, pyr., DCM, rt, 2 h, 90\%; c) 1-bromo-n-chloro-octane, $\mathrm{K}_{2} \mathrm{CO}_{3}$, DMF, rt, $12 \mathrm{~h}$, followed by $\mathrm{NaN}_{3}$, DMF, overnight $60{ }^{\circ} \mathrm{C}, 80 \%-90 \%$; d) MOM-Cl, DIPEA, DCM, rt, $12 \mathrm{~h}$; e) $\mathrm{K}_{2} \mathrm{CO}_{3}$, propargyl bromide, DMF, $\mathrm{rt} / 2 \mathrm{~h}, 85 \%-90 \%$; f) $3 \mathrm{~N} \mathrm{HCl}$, acetone, reflux/overnight, $55 \%-60 \%$; g) $\mathrm{CuSO}_{4} \cdot 5 \mathrm{H}_{2} \mathrm{O}(1 \mathrm{~mol} \%)$, sodium ascorbate (5 mol \%), $\mathrm{DMF} / \mathrm{H}_{2} \mathrm{O}(1: 1)$, rt, overnight, $80 \%-95 \%$; h) $\mathrm{SO}_{3} / \mathrm{Me}_{3} \mathrm{~N}, \mathrm{TEA}, \mathrm{CH}_{3} \mathrm{CN}$, microwave, $90{ }^{\circ} \mathrm{C}$, 0.5-6 h, 85\%-90\%; i) $\mathrm{K}_{2} \mathrm{CO}_{3}$, dibromobutane (0.5 equiv), DMF, rt, $6 \mathrm{~h}, 85 \%-90 \%$; j) $p$-toluenesulfonic acid, $\mathrm{MeOH}$, reflux, $48 \mathrm{~h}, 55 \%-65 \%$.

\subsection{Inhibition of Human Plasmin by the Library of NSGMS}

The library of synthetic NSGMs was screened for inhibition of human Lys-plasmin using the chromogenic substrate hydrolysis assay, as described earlier [27], under near physiological conditions in Tris- $\mathrm{HCl}$ buffer, $\mathrm{pH} 7.4$, containing $150 \mathrm{mM} \mathrm{NaCl}$ at $37{ }^{\circ} \mathrm{C}$. Initial screening was performed at $400 \mu \mathrm{M}$ NSGM concentration and only those agents that displayed $\geq 70 \%$ inhibition were considered for detailed $I C_{50}$ characterization. As shown in Figure 2, none of the monomeric NSGMs including the highly sulfated disaccharide sucrose octasulfate 17 inhibited plasmin more than $70 \%$. In contrast, several dimeric scaffolds exhibited considerable promise. For example, flavonoid-quinazolinone heterodimers 28-34 and flavonoid homodimers 50 and 53 inhibited plasmin more than 90\%. Likewise, 7 out of 13 quinazolinone dimers (40 and $\mathbf{4 2 - 4 7 )}$ ) exhibited plasmin inhibition. Thus, the size and distribution of functional groups appeared to be important to induce plasmin inhibition.

To measure the potency and efficacy of these 16 plasmin inhibitors, the sigmoidal dose-dependence of plasmin inhibition was fitted using the logistic equation (See Equation (1) in Experimental Section) to calculate all inhibition parameters (Table 1). Important to emphasize here that the potency of NSGM-based inhibitors was evaluated by measuring their $I C_{50}$ 's (X-axis), whereas the efficacy was assessed by measuring the overall change in residual plasmin activity (\%) $\left(\Delta Y=Y_{M}-Y_{0}\right)$ (Y-axis). Representative inhibition profiles are shown in Figure 3. Inhibitors $\mathbf{3 1}$ and $\mathbf{3 2}$ were found to be most potent with $I C_{50}$ of $56 \pm 2 \mu \mathrm{M}$ and $45 \pm 2 \mu \mathrm{M}$, respectively, and efficacy of $87 \% \pm 4 \%$ and $105 \% \pm 6 \%$, respectively. The two inhibitors are structurally related and belong to the chemical class of flavonoid-quinazolinone hetero-dimers having a quinazolinone moiety substituted with one sulfate group at 4'-position and flavonoid structure with four sulfate groups at positions-3,7,3', and 4'. The two 
units linked through a tetrazole-containing 11 and 12-atom linker, respectively. The two base scaffolds are connected at $N^{3}$-position of quinazolinone and $O^{5}$-position of flavonoid.

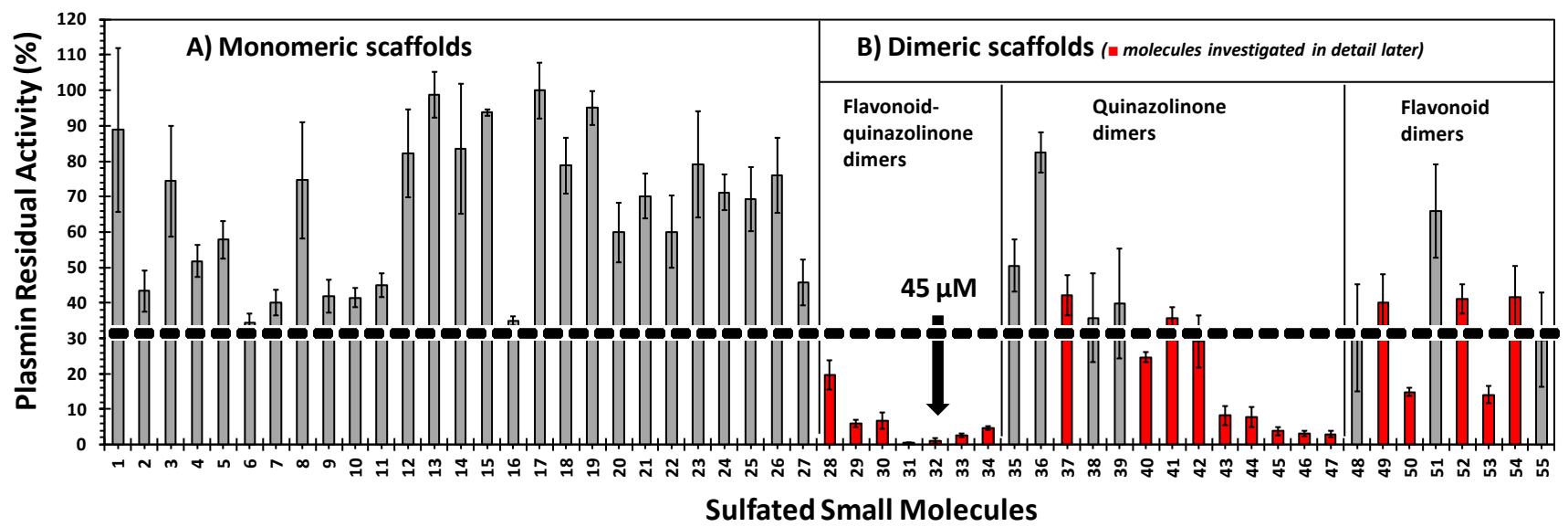

Figure 2. Initial screening of the 55 sulfated small molecules against human plasmin. Screening was performed in $50 \mathrm{mM}$ Tris- $\mathrm{HCl}$ buffer at $150 \mathrm{mM} \mathrm{NaCl}, \mathrm{pH} \mathrm{7.4}$, and $37{ }^{\circ} \mathrm{C}$ using the corresponding chromogenic substrate hydrolysis assay in the presence of $400 \mu \mathrm{M}$ inhibitor $(n \geq 2)$. The error bars represents one standard deviation.

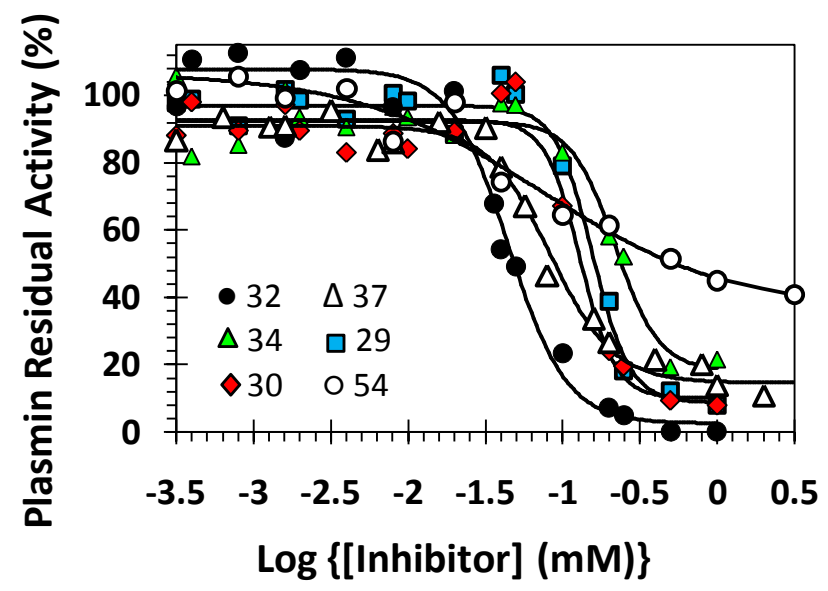

Figure 3. Representative profiles of direct inhibition of human plasmin by sulfated molecules. The inhibition of plasmin was measured spectrophotometrically through a chromogenic substrate hydrolysis assay at $\mathrm{pH} 7.4$ and $37^{\circ} \mathrm{C}$. Solid lines represent sigmoidal fits to the data to obtain $I C_{50}$, HS, $Y_{M}$, and $Y_{O}$ using Equation (1), as described in the Experimental Procedures.

Table 1. Plasmin inhibition by sulfated small molecules. ${ }^{\text {a }}$

\begin{tabular}{cccc}
\hline Plasmin Inhibitor & $\boldsymbol{I C}_{\boldsymbol{5 0}}(\boldsymbol{\mu M})$ & $\mathbf{H S}$ & $\boldsymbol{\Delta Y} \boldsymbol{\%}$ \\
\hline $\mathbf{2 8}$ & $149 \pm 5.6^{\mathrm{b}}$ & $3.3 \pm 0.7$ & $82 \pm 4$ \\
$\mathbf{2 9}$ & $157 \pm 5.0$ & $3.6 \pm 0.7$ & $88 \pm 4$ \\
$\mathbf{3 0}$ & $220 \pm 11$ & $3.0 \pm 1.3$ & $74 \pm 7$ \\
$\mathbf{3 1}$ & $56 \pm 2$ & $3.2 \pm 0.8$ & $87 \pm 4$ \\
$\mathbf{3 2}$ & $45 \pm 2$ & $2.3 \pm 0.7$ & $105 \pm 6$ \\
$\mathbf{3 3}$ & $128 \pm 8$ & $1.8 \pm 0.4$ & $89 \pm 7$ \\
\hline
\end{tabular}


Table 1. Cont.

\begin{tabular}{cccc}
\hline Plasmin Inhibitor & $\boldsymbol{I C}_{\boldsymbol{5 0}}(\boldsymbol{\mu M})$ & $\mathbf{H S}$ & $\boldsymbol{\Delta Y} \%$ \\
\hline $\mathbf{3 4}$ & $130 \pm 6$ & $3.9 \pm 1.0$ & $83 \pm 5$ \\
$\mathbf{3 5}$ & $642 \pm 78$ & $1.4 \pm 0.4$ & $88 \pm 11$ \\
$\mathbf{3 6}$ & $>1000$ & $\mathrm{ND}^{\mathrm{c}}$ & $\mathrm{ND}$ \\
$\mathbf{3 7}$ & $84 \pm 4$ & $2.1 \pm 0.4$ & $76 \pm 3$ \\
$\mathbf{3 8}$ & $>400$ & $\mathrm{ND}$ & $\mathrm{ND}$ \\
$\mathbf{3 9}$ & $>400$ & $\mathrm{ND}$ & $\mathrm{ND}$ \\
$\mathbf{4 0}$ & $239 \pm 73$ & $1.1 \pm 0.6$ & $87 \pm 29$ \\
$\mathbf{4 1}$ & $125 \pm 9$ & $4.0 \pm 1.8$ & $54 \pm 5$ \\
$\mathbf{4 2}$ & $161 \pm 24$ & $1.0 \pm 0.2$ & $92 \pm 4$ \\
$\mathbf{4 3}$ & $183 \pm 43$ & $1.0 \pm 0.3$ & $94 \pm 21$ \\
$\mathbf{4 4}$ & $137 \pm 11$ & $1.0 \pm 0.2$ & $102 \pm 9$ \\
$\mathbf{4 5}$ & $98 \pm 9$ & $1.7 \pm 0.6$ & $94 \pm 6$ \\
$\mathbf{4 6}$ & $111 \pm 7$ & $2.4 \pm 0.4$ & $95 \pm 2$ \\
$\mathbf{4 7}$ & $89 \pm 7$ & $1.9 \pm 0.6$ & $98 \pm 7$ \\
$\mathbf{4 8}$ & $621 \pm 185$ & $1.3 \pm 0.4$ & $89 \pm 36$ \\
$\mathbf{4 9}$ & $277 \pm 61$ & $1.8 \pm 1.0$ & $75 \pm 22$ \\
$\mathbf{5 0}$ & $185 \pm 68$ & $1.4 \pm 0.2$ & $38 \pm 15$ \\
$\mathbf{5 1}$ & $\sim 2830$ & $\mathrm{ND}$ & $\mathrm{ND}$ \\
$\mathbf{5 2}$ & $76 \pm 12$ & $1.0 \pm 0.2$ & $72 \pm 9$ \\
$\mathbf{5 3}$ & $209 \pm 25$ & $0.6 \pm 0.1$ & $105 \pm 8$ \\
$\mathbf{5 4}$ & $75 \pm 25$ & $0.7 \pm 0.3$ & $71 \pm 18$ \\
$\mathbf{5 5}$ & $>400$ & $\mathrm{ND}$ & $\mathrm{ND}$ \\
\hline
\end{tabular}

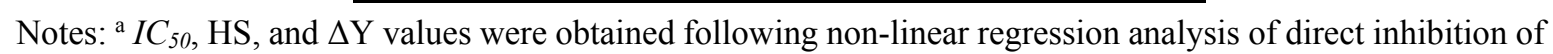
human plasmin in $\mathrm{pH} 7.4$ buffer at $37^{\circ} \mathrm{C}$. Inhibition was monitored by spectrophotometric measurement of the residual enzyme activity. See details under Experimental Section. ${ }^{b}$ Errors represent standard error calculated using global fit of the data. ${ }^{\mathrm{c}} \mathrm{ND}$ means not determined.

\subsection{Structure-Activity Relationship of Plasmin Inhibition}

To better understand the optimal structural features required for plasmin inhibition, we measured the inhibition profile for 12 additional sulfated NSGMs from the library. The class of sulfated flavonoid-quinazolinone dimers 28-34 was the most potent among the three dimeric classes studied with $I C_{50}$ values of 45-220 $\mu \mathrm{M}$ (Figure 2 and Table 1). The efficacy of inhibition was also found to be high $(>74 \%)$. As expected, longer linkers in sulfated dimers, such as the 13-atom and 14-atom linkers in 33 and 34, respectively, diminished the potency $\sim 3$-fold relative to 32, which has a 12-atom linker. Extended linkers are typically expected to increase the structural flexibility of NSGMs which may thermodynamically disfavor their binding to plasmin. The optimal position of a sulfate group on the quinazolinone unit could be either meta- $\left(\mathbf{2 8}, I_{50} 149 \mu \mathrm{M}\right)$ or para- $\left(\mathbf{2 9}, I_{50} 157 \mu \mathrm{M}\right)$ but not ortho- (30, IC $50220 \mu \mathrm{M})$. Replacing only the tetrasulfated flavonoid scaffold in inhibitors 31 and 32 with the para-sulfated quinazolinone moiety in $\mathbf{4 2}$ and $\mathbf{4 3}$, respectively, decreased the inhibition potency >-4 fold (Table 1). This implies that the heterodimeric scaffolds display superior plasmin inhibitory properties. The impact of other variables, e.g., even shorter linker length, number of sulfate groups on 
quinazolinone and/or flavonoid moities, and variation in linker attachment position, in the class of heterodimers remains to be tested.

The class of quinazolinone homodimers (35-47) exhibited highly variable inhibition potency $(84 \pm 4 \mu \mathrm{M}$ to $>1000 \mu \mathrm{M})$ and efficacy $(54 \% \pm 5 \%$ to $102 \% \pm 9 \%)$. The most potent inhibitor in this series was the trisulfated inhibitor 37 (IC50 $84 \pm 4 \mu \mathrm{M}$; efficacy 76\% $\pm 3 \%$ ). Inhibitor 37 has an 8-atom linker and one para-sulfate group on one quinazolinone unit and two meta-sulfate groups on the other unit. Replacing one of the meta-position sulfate groups by an acetoxy group as in $\mathbf{3 6}$ or hydrogen atom as in $\mathbf{3 8}$ and $\mathbf{3 9}$ significantly diminished the inhibitory potency by 125 -fold and 5-fold, respectively. This further emphasizes the importance of sulfate group for inhibition of plasmin. Yet, considering the para,para-disulfated inhibitors 40-47, changing the linker length from eight to 16 or linker nature from 1,4-triazole- to 1,5-triazole or bis-1,4-triazole had only a marginal impact on the $I C_{50}(89-183 \mu \mathrm{M})$.

Finally, the class of flavonoid homodimers $(\mathbf{4 8 - 5 5})$ demonstrated moderate to very weak potency $\left(I C_{50} 75-2830 \mu \mathrm{M}\right)$ and highly variable efficacy $(38 \% \pm 15 \%-105 \% \pm 8 \%)$. The two most potent NSGMs, $\mathbf{5 2}$ and 54, displayed $I C_{50}$ values of $76 \pm 12 \mu \mathrm{M}$ and $75 \pm 25 \mu \mathrm{M}$, respectively, and similar efficacy of $72 \% \pm 9 \%$ and $71 \% \pm 18 \%$. The two molecules have two identical tetrasulfated flavonoid moieties connected by 4-atom linker, which is saturated in the former and unsaturated in the latter. In this class, it appears that the 4-atom linker is optimal because a 2 -atom linker (i.e., 50) and a 5-atom linker (i.e., 53 ) induce loss in potency of 2- and 3-fold, respectively. Likewise, other structural variations in number of sulfate groups (8 versus 6 sulfates) or position of attachment (5,5-versus 3',3'-) for the two flavonoid moieties linked by identical linkers (i.e., 48, 51, and 55) are detrimental for activity (8-, 37-, and 5-fold).

\subsection{Mechanism of Plasmin Inhibition by NSGMs $\mathbf{3 2}$ and $\mathbf{5 2}$}

To understand the basis for NSGMs' plasmin inhibitory potential, the kinetics of Spectrozyme PL, a chromogenic tripeptide substrate, hydrolysis by human plasmin was measured at $\mathrm{pH} 7.4$ and $37{ }^{\circ} \mathrm{C}$ in the presence of inhibitors 32 and 52. As expected, the initial rate of hydrolysis varied in a hyperbolic manner with increasing concentration of Spectrozyme PL at all concentrations of the NSGMs (Figure 4) from which the Michaelis constant ( $\left.\mathrm{K}_{\mathrm{M}}\right)$ and maximal velocity of the reaction ( $\mathrm{V}_{\mathrm{MAX}}$ ) were calculated (Table 2). The $\mathrm{K}_{\mathrm{M}}$ for Spectrozyme PL in the absence of 32 was found to be $0.07 \pm 0.01 \mathrm{mM}$, which remained essentially unchanged despite an increase in the inhibitor's concentration to $250 \mu \mathrm{M}$ $(0.06 \pm 0.01 \mathrm{mM})$. In contrast, the $\mathrm{V}_{\mathrm{MAX}}$ decreased 5.5-fold from $69.6 \pm 3.3 \mathrm{mAU} / \mathrm{min}$ to $12.5 \pm 1.3 \mathrm{mAU} / \mathrm{min}$ for the same range of inhibitor concentration. In the presence of NSGM 52, both $\mathrm{K}_{\mathrm{M}}$ and $\mathrm{V}_{\mathrm{MAX}}$ for Spectrozyme PL decreased approximately 3.5-fold from that in its absence (Table 2). Thus, the two inhibitors (32 and 52) appear to differ slightly in their mechanism of plasmin inhibition. While the affinity of the substrate remains unaffected by 32, it increases in the presence of $\mathbf{5 2}$. Yet, both NSGMs bring about a decrease in the rate of plasmin activity, which is the basis for their functional effect. Technically, the mechanism induced by $\mathbf{3 2}$ is called noncompetitive inhibition, while that induced by $\mathbf{5 2}$ is called uncompetitive inhibition. While uncompetitive inhibitor $\mathbf{5 2}$ requires that a plasmin-substrate Michaelis complex must be formed, noncompetitive inhibitor 32 can occur with or without the substrate present. In either case, the NSGMs appear to bring about changes in the active site of plasmin that induces dysfunction in its catalytic apparatus. Both mechanisms arise from allosteric binding of NSGMs 32 and $\mathbf{5 2}$ to plasmin. Thus, the NSGMs studied in this work parallel the growing class of allosteric inhibitors 
of heparin-binding enzymes reported in the literature to date, such as low molecular weight lignins [27], sulfated benzofurans [34,35], sulfated tetrahydroisoquinolines [36], sulfated quinazolinones [37], and sulfated pentagalloyl glucopyranoses [38,39].

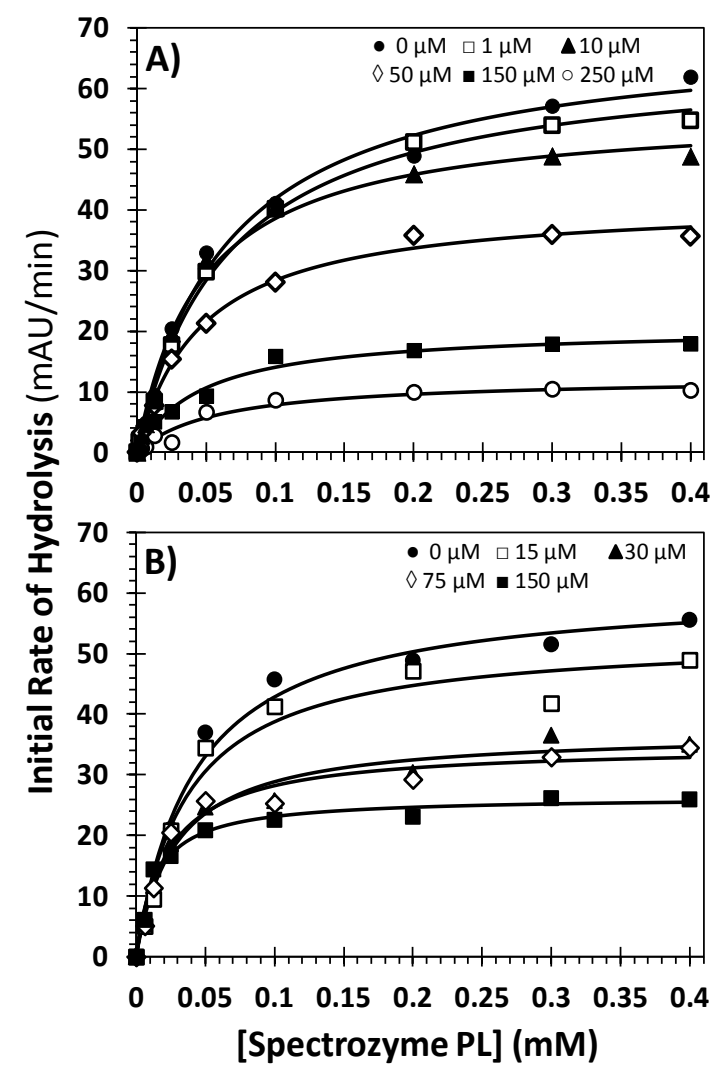

Figure 4. Michaelis-Menten kinetics of chromogenic substrate hydrolysis by human plasmin in the presence of sulfated flavonoid-quinazolinone heterodimer (32) (A) and flavonoid homodimer (52) (B). The initial rate of hydrolysis at various substrate concentrations was measured spectrophotometrically in $\mathrm{pH} 7.4$ buffer at $37{ }^{\circ} \mathrm{C}$. Solid lines represent nonlinear regressional fits to the data by the standard Michaelis-Menten equation to yield $\mathrm{K}_{\mathrm{M}}$ and $\mathrm{V}_{\mathrm{MAX}}$.

Table 2. Hydrolysis of Spectrozyme PL by plasmin in presence of NSGMs $\mathbf{3 2}$ and $\mathbf{5 2}$ a $^{\text {a }}$

\begin{tabular}{cccc}
\hline Inhibitor & Conc. $(\boldsymbol{\mu M})$ & $\mathbf{K}_{\mathbf{M}}(\mathbf{m M})$ & $\mathbf{V}_{\mathbf{M A X}}(\mathbf{m A U} / \mathbf{m i n})$ \\
\hline \multirow{3}{32}{} & 0 & $0.07 \pm 0.01^{\mathrm{b}}$ & $69.6 \pm 3.3$ \\
& 1 & $0.07 \pm 0.01$ & $65.8 \pm 2.1$ \\
& 10 & $0.05 \pm 0.01$ & $56.4 \pm 2.3$ \\
& 50 & $0.05 \pm 0.01$ & $41.4 \pm 1.6$ \\
& 150 & $0.05 \pm 0.01$ & $20.7 \pm 1.1$ \\
$\mathbf{5 2}$ & 250 & $0.06 \pm 0.01$ & $12.5 \pm 1.3$ \\
& 0 & $0.04 \pm 0.01$ & $61.0 \pm 2.4$ \\
& 15 & $0.04 \pm 0.01$ & $52.9 \pm 2.9$ \\
& 30 & $0.03 \pm 0.01$ & $37.0 \pm 1.5$ \\
& 75 & $0.023 \pm 0.004$ & $34.8 \pm 1.5$ \\
& 150 & $0.014 \pm 0.002$ & $26.4 \pm 0.8$ \\
\hline
\end{tabular}

Notes: ${ }^{a} \mathrm{~K}_{\mathrm{M}}$ and $\mathrm{V}_{\mathrm{MAX}}$ values of plasmin chromogenic substrate hydrolysis by human plasmin were measured as described in the Experimental Section. mAU indicates milliabsorbance units. ${ }^{b}$ Error represents \pm 1 S.E. 


\subsection{Selectivity Studies: Direct Inhibition of Thrombin and Factor Xa of the Coagulation Cascade}

The rationale behind targeting an allosteric site on plasmin was to achieve inhibition specificity over the closely related serine proteases. In contrast to active sites, allosteric sites are not as highly conserved and therefore present a powerful opportunity for discovering a selective modulator of enzyme function. To assess the specificity features of inhibitors 31, 32, 52, and 54, two closely related coagulation enzymes, thrombin and factor Xa, were studied. Using appropriate small peptide-based chromogenic substrates, the fractional residual thrombin and factor $\mathrm{Xa}$ activities were measured under the physiological condition of $\mathrm{pH} 7.4$ and $37^{\circ} \mathrm{C}$. The $I C_{50}$ values of these inhibitors against thrombin were $>500 \mu \mathrm{M}$ suggesting a selectivity index of at least $7-10$-fold, whereas the $I C_{50}$ values of same inhibitors against factor Xa were $>250 \mu \mathrm{M}$ suggesting a selectivity index of about 5-fold. Thus, allosteric inhibitors of plasmin identified in this study are selective.

\section{Experimental Section}

\subsection{Chemicals, Reagents, Analytical Chemistry, Enzymes, Peptides}

Anhydrous $\mathrm{CH}_{2} \mathrm{Cl}_{2}$, THF, $\mathrm{CH}_{3} \mathrm{CN}$, DMF, DMA and acetone were purchased from Sigma-Aldrich (Milwaukee, WI, USA) or Fisher (Pittsburgh, PA, USA) and used as such. Other solvents used were of reagent gradient and used as purchased. Analytical TLC was performed using UNIPLATE ${ }^{\mathrm{TM}}$ silica gel GHLF 250 um pre-coated plates (Analtech, Newark, DE, USA). Column chromatography was performed using silica gel (200-400 mesh, $60 \AA$ ) from Sigma-Aldrich. Chemical reactions sensitive to air or moisture were carried out under nitrogen atmosphere in oven-dried glassware. Reagent solutions, unless otherwise noted, were handled under a nitrogen atmosphere using syringe techniques. Flash chromatography was performed using Teledyne ISCO (Lincoln, NE, USA) Combiflash RF system and disposable normal silica cartridges of 30-50 $\mu$ particle size, 230-400 mesh size and $60 \AA$ pore size. The flow rate of the mobile phase was in the range of 18 to $35 \mathrm{~mL} / \mathrm{min}$ and mobile phase gradients of ethyl acetate/hexanes and $\mathrm{CH}_{2} \mathrm{Cl}_{2} / \mathrm{CH}_{3} \mathrm{OH}$ were used to elute compounds. Human plasmin was obtained from Haematologic Technologies (Essex Junction, VT, USA). Stock solutions of plasmin and thrombin were prepared in $50 \mathrm{mM}$ Tris-HCl buffer, $\mathrm{pH} 7.4$, containing $150 \mathrm{mM} \mathrm{NaCl}, 0.1 \%$ PEG8000, and 0.02\% Tween80. Stock solution of factor Xa was prepared in $20 \mathrm{mM}$ Tris-HCl buffer, $\mathrm{pH} 7.4$, containing $100 \mathrm{mM} \mathrm{NaCl}, 2.5 \mathrm{mM} \mathrm{CaCl}_{2}, 0.1 \%$ PEG8000, and 0.02\% Tween80. Plasmin (Spectrozyme PL), thrombin (Spectrozyme TH), and factor Xa (Spectrozyme FXa) chromogenic substrates were all obtained from American Diagnostica (Greenwich, CT, USA).

\subsection{Chemical Characterization of Compounds}

${ }^{1} \mathrm{H}$ - and ${ }^{13} \mathrm{C}-\mathrm{NMR}$ were recorded on a Bruker-400 $\mathrm{MHz}$ spectrometer in either $\mathrm{CDCl}_{3}, \mathrm{CD}_{3} \mathrm{OD}$, acetone- $d_{6}$, DMSO- $d_{6}$, or $\mathrm{D}_{2} \mathrm{O}$. Signals, in part per million (ppm), are either relative to the internal standard or to the residual peak of the solvent. The NMR data are reported as chemical shift (ppm), multiplicity of signal ( $\mathrm{s}=$ singlet, $\mathrm{d}=$ doublet, $\mathrm{t}=$ triplet, $\mathrm{q}=$ quartet, $\mathrm{dd}=$ doublet of doublet, $\mathrm{m}=$ multiplet), coupling constants $(\mathrm{Hz})$, and integration. ESI-MS of compounds were recorded using Waters Acquity TQD MS spectrometer in positive or negative ion mode. Samples were dissolved in methanol and infused at a rate 
of $20 \mu \mathrm{L} / \mathrm{min}$. For HRMS measurements, a Perkin Elmer AxION 2 TOF MS was used in negative ion mode. Ionization conditions on both instruments were optimized for each compound to maximize the ionization of the parent ion. Generally, the extractor voltage was set to $3 \mathrm{~V}$, the Rf lens voltage was $0.1 \mathrm{~V}$, the source block temperature was set to $150{ }^{\circ} \mathrm{C}$, and the desolvation temperature was about $250{ }^{\circ} \mathrm{C}$. The purity of each final compound was greater than $95 \%$ as determined by UPLC-MS. We report here the characterization data for inhibitors 31, 32, 52, and 54. The characterization data of all inhibitors and their intermediates are reported in the Supplementary Information.

3-(8-(4-((2-(3,4-O,O-Disulfonato-phenyl)-3,7-O,O-disulfonato-4-oxo-4H-chromen-5-yloxy)methyl)1H-1,2,3-triazol-1-yl)heptyl)-2-(4-O-sulfonato-phenyl)quinazolin-4(3H)-one, Pentasodium salt (31). ${ }^{1} \mathrm{H}-\mathrm{NMR}$ (DMSO-d6): $8.42(\mathrm{~d}, J=8.7 \mathrm{~Hz}, 2 \mathrm{H}), 8.31-8.28(\mathrm{~m}, 1 \mathrm{H}), 8.15-8.11(\mathrm{~m}, 3 \mathrm{H}), 7.93-7.9$ (m, $2 \mathrm{H}), 7.65-7.62(\mathrm{~m}, 2 \mathrm{H}), 7.34(\mathrm{~d}, J=8.7 \mathrm{~Hz}, 2 \mathrm{H}), 7.13-7.07(\mathrm{~m}, 1 \mathrm{H}), 6.85-6.81(\mathrm{~m}, 1 \mathrm{H}), 5.24(\mathrm{~s}, 2 \mathrm{H})$, $4.71(\mathrm{t}, J=6.4 \mathrm{~Hz}, 2 \mathrm{H}), 4.37(\mathrm{t}, J=7.9 \mathrm{~Hz}, 2 \mathrm{H}), 1.93-1.85(\mathrm{~m}, 4 \mathrm{H}) 1.55-1.24(\mathrm{~m}, 6 \mathrm{H}) .{ }^{13} \mathrm{C}-\mathrm{NMR}\left(\mathrm{D}_{2} \mathrm{O}\right)$ : $169.04,160.39,157.96,155.86,154.12,148.67,143.76,135.18,132.09,129.78,128.80,127.34,124.34$, 123.16, 119.08, 115.13, 114.19, 114.03, 113.96, 66.76, 52.80, 49.42, 29.23, 28.61, 28.35, 25.29, 25.18. MS (ESI) calculated for $\mathrm{C}_{39} \mathrm{H}_{30} \mathrm{~N}_{5} \mathrm{Na}_{5} \mathrm{O}_{24} \mathrm{~S}_{5}[(\mathrm{M}-\mathrm{Na})]^{-}, m / z 1203.94$, found $[(\mathrm{M}-2 \mathrm{Na})]^{2-}, m / z 590.38$.

3-(8-(4-((2-(3,4-O,O-Disulfonato-phenyl)-3,7-O,O-disulfonato-4-oxo-4H-chromen-5-yloxy)methyl)1H-1,2,3-triazol-1-yl)octyl)-2-(4-O-sulfonato-phenyl)quinazolin-4(3H)-one, Pentasodium salt (32). ${ }^{1} \mathrm{H}-\mathrm{NMR}$ (DMSO- $\left.d 6\right): 8.44(\mathrm{~d}, J=8.8 \mathrm{~Hz}, 2 \mathrm{H}), 8.32-8.27(\mathrm{~m}, 1 \mathrm{H}), 8.1-8.12(\mathrm{~m}, 3 \mathrm{H}), 7.9-7.92$ (m, 2 H), 7.6-7.61 (m, $2 \mathrm{H}), 7.34(\mathrm{~d}, J=8.8 \mathrm{~Hz}, 2 \mathrm{H}), 7.1-7.07(\mathrm{~m}, 1 \mathrm{H}), 6.8-6.82(\mathrm{~m}, 1 \mathrm{H}), 5.23(\mathrm{~s}, 2 \mathrm{H}), 4.71$ $(\mathrm{t}, J=6.4 \mathrm{~Hz}, 2 \mathrm{H}), 4.38(\mathrm{t}, J=7.9 \mathrm{~Hz}, 2 \mathrm{H}), 1.9-1.85(\mathrm{~m}, 4 \mathrm{H}) 1.5-1.23(\mathrm{~m}, 8 \mathrm{H}) .{ }^{13} \mathrm{C}-\mathrm{NMR}\left(\mathrm{D}_{2} \mathrm{O}\right)$ : $169.03,160.23,158.86,156.07,151.06,148.58,142.20,134.15,131.82,129.96,128.96,127.30,126.79$, 124.30, 123.21, 119.83, 115.34, 114.37, 114.17, 66.81, 52.81, 49.40, 29.70, 28.54, 28.27, 28.12, 25.78, 25.44. MS (ESI) calculated for $\mathrm{C}_{40} \mathrm{H}_{32} \mathrm{~N}_{5} \mathrm{Na}_{5} \mathrm{O}_{24} \mathrm{~S}_{5}[(\mathrm{M}-\mathrm{Na})]^{-}, m / z 1217.95$, found $[(\mathrm{M}-2 \mathrm{Na})]^{2-}$, $m / z 597.39$.

5,5'-(Butane-1,4-diylbis(oxy))bis(2-(3,4-O,O-disulfonato-phenyl)-3,7-O,O-disulfonato-4H-chromen-4one), Octasodium salt (52). ${ }^{1} \mathrm{H}-\mathrm{NMR}$ (DMSO-d6): 8.15-8.07 (m, $\left.4 \mathrm{H}\right), 7.64(\mathrm{~d}, J=9 \mathrm{~Hz}, 2 \mathrm{H}), 7.04$ (d, $J=1.8 \mathrm{~Hz}, 2 \mathrm{H}), 6.72$ (s, $2 \mathrm{H}), 4.15$ (s, $4 \mathrm{H}), 2.11$ (s, 4H). ${ }^{13} \mathrm{C}-\mathrm{NMR}$ (DMSO-d6): 173.0, 159.41, 158.31, 157.01, 153.27, 146.41, 142.92, 135.30, 124.50, 123.59, 119.80, 118.77, 109.42, 100.02, 98.85, 68.81, 25.5. ESI-MS calculated for $\mathrm{C}_{34} \mathrm{H}_{18} \mathrm{Na}_{8} \mathrm{O}_{38} \mathrm{~S} 8[(\mathrm{M}+\mathrm{Na})]^{+}, m / z 1497.95$, found $[(\mathrm{M}-8 \mathrm{Na}+8 \mathrm{HxA})+2 \mathrm{HxA}]^{2+}$, $\mathrm{m} / z 1156.367$.

(E)-5,5'-(But-2-ene-1,4-diylbis(oxy))bis(2-(3,4-O,O-disulfonato-phenyl)-3,7-O,O-disulfonato-4Hchromen-4-one), Octasodium salt (54). ${ }^{1} \mathrm{H}-\mathrm{NMR}$ (DMSO-d $): 8.07(\mathrm{~d}, J=2.2 \mathrm{~Hz}, 2 \mathrm{H}), 8.0(\mathrm{~d}, J=6.7 \mathrm{~Hz}$, $2 \mathrm{H}), 6.98(\mathrm{~d}, J=1.9 \mathrm{~Hz}, 2 \mathrm{H}), 6.63(\mathrm{~d}, J=1.9 \mathrm{~Hz}, 2 \mathrm{H}), 6.39$ (s, $2 \mathrm{H}), 4.64$ (s, $4 \mathrm{H}) .{ }^{13} \mathrm{C}-\mathrm{NMR}$ (DMSO- $\left.d_{6}\right)$ : 173.24, 158.43, 158.25, 157.08, 154.28, 148.43, 143.82, 134.31, 123.50, 123.28, 119.84, 118.78, 108.45, 100.05, 98.87, 75.81. ESI-MS calculated for $\mathrm{C}_{34} \mathrm{H}_{16} \mathrm{Na}_{8} \mathrm{O}_{38} \mathrm{~S}_{8}[(\mathrm{M}+\mathrm{Na})]^{+}, \mathrm{m} / z$ 1495.91, found $[(\mathrm{M}-8 \mathrm{Na}+8 \mathrm{HxA})+2 \mathrm{HxA}]^{2+}, m / z 1155.620$. 


\subsection{General Procedure of Chemical Sulfation of Small Molecules}

Sulfation of polyphenolic precursors was achieved using microwave assisted chemical sulfation as described earlier [30-42]. Briefly, to a stirred solution of polyphenol in anhydrous $\mathrm{CH}_{3} \mathrm{CN}(1-5 \mathrm{~mL})$ at room temperature, $\mathrm{Et}_{3} \mathrm{~N}$ (10 equivalents per $-\mathrm{OH}$ group) and $\mathrm{Me}_{3} \mathrm{~N}: \mathrm{SO}_{3}$ complex (6 equivalents per $-\mathrm{OH}$ ) was added. The reaction vessel was sealed and microwaved (CEM Discover, Cary, NC, USA) for $0.5-8 \mathrm{~h}$ at $90-100{ }^{\circ} \mathrm{C}$. The reaction mixture was cooled and transferred to a round bottom flask and volume reduced as much as possible under low pressure conditions at $25^{\circ} \mathrm{C}$. The reaction mixture was then directly loaded on to a flash chromatography column and purified using dichloromethane and methanol solvent system (5\%-20\%) to obtain the sulfated molecules. The samples were concentrated and reloaded onto a SP Sephadex C-25 column for sodium exchange. Appropriate fractions were pooled, concentrated in vacuo, and lyophilized to obtain a white powder. The reaction time was optimized depending on the scaffold and it ranged from $30 \mathrm{~min}$ to $8 \mathrm{~h}$ at $90-100{ }^{\circ} \mathrm{C}$. All microwave-assisted sulfation reactions were quantitative with a minimum yield of $75 \%$.

\subsection{Direct Inhibition of Human Plasmin by Sulfated Small Molecules}

Direct inhibition of human Lys-plasmin was measured using a chromogenic substrate hydrolysis assay on a microplate reader (FlexStation III, Molecular Devices, Sunnyvale, CA, USA), as reported earlier [27]. Briefly, to each well of a 96-well microplate containing $85 \mu \mathrm{L}$ of $50 \mathrm{mM}$ Tris-HCl buffer, pH 7.4, containing $150 \mathrm{mM} \mathrm{NaCl}, 0.1 \%$ PEG8000, and $0.02 \%$ Tween 80 at $37{ }^{\circ} \mathrm{C}$ was added $5 \mu \mathrm{L}$ potential NSGM-based inhibitor (20-100 mM aqueous solution) (or vehicle alone) and $5 \mu \mathrm{L}$ enzyme. The final concentration of the enzyme was $20 \mathrm{nM}$. After $5 \mathrm{~min}$ incubation, $5 \mu \mathrm{L}$ of $1 \mathrm{mM}$ Spectrozyme PL was rapidly added and the residual enzyme activity was measured from the initial rate of increase in A405. Relative residual enzyme activity $(Y)$ as a function of the concentration of sulfated molecule was fitted using logistic equation 1 to obtain the potency $\left(I_{50}\right)$, efficacy $(\Delta Y)$ and Hill slope $(H S)$ of inhibition. In this equation, $Y_{\mathrm{M}}$ and $Y_{0}$ are the maximal and minimal values of $Y$ :

$$
Y=Y_{0}+\frac{Y_{M}-Y_{0}}{1+10^{\left(\log [\text { Inhibitor }]_{0}-\log I C_{50}\right) \times H S}}
$$

In this equation, $Y$ is the ratio of residual plasmin activity in the presence of inhibitor to that in its absence (fractional residual activity). $Y_{M}$ and $Y_{0}$ are the maximum and minimum possible values of the fractional residual proteinase activity. The difference between these two values is used to evaluate the inhibitor's efficacy to reduce the residual enzyme activity under the assay condition. $I C_{50}$ is the concentration of the inhibitor that results in 50\% inhibition of enzyme activity and it is used to evaluate its potency.

\subsection{Michaelis-Menten Kinetics of Spectrozyme PL Hydrolysis by Plasmin in the Presence of Molecules $\mathbf{3 2}$ and $\mathbf{5 2}$}

The initial rate of Spectrozyme PL hydrolysis by human plasmin $(20 \mathrm{nM})$ was monitored from the linear increase in absorbance at $405 \mathrm{~nm}$ corresponding to less than $10 \%$ consumption of the substrate. The initial rate was measured as a function of various concentrations of the substrate $(0-400 \mu \mathrm{M})$ in the presence of fixed concentration of inhibitor (32) $(0-250 \mu \mathrm{M})$ or inhibitor (52) $(0-150 \mu \mathrm{M})$ in $50 \mathrm{mM}$ 
Tris- $\mathrm{HCl}$ buffer, $\mathrm{pH} 7.4,150 \mathrm{mM} \mathrm{NaCl}$ at $37^{\circ} \mathrm{C}$. The data were fitted by Michaelis-Menten Equation (2) to determine $K_{M \text {, app }}$ and $\mathrm{V}_{\mathrm{MAX}}$

$$
V=\frac{V_{M A X}[S]}{K_{M}+[S]}
$$

\subsection{Selectivity Studies: Direct Inhibition of Thrombin and Factor Xa of the Coagulation Cascade}

Direct inhibition of thrombin and factor Xa by 31, 32, 52, and 54 was measured using a chromogenic substrate hydrolysis assay on a microplate reader (FlexStation III, Molecular Devices), as reported earlier [43]. Briefly, to each well of a 96-well microplate containing $185 \mu \mathrm{L}$ of $20-50 \mathrm{mM}$ Tris- $\mathrm{HCl}$ buffer, pH 7.4, containing 100-150 mM NaCl, 0.1\% PEG8000 and $0.02 \%$ Tween80 at either $25{ }^{\circ} \mathrm{C}$ (thrombin) or $37^{\circ} \mathrm{C}$ (factor Xa) was added $5 \mu \mathrm{L}$ of $10-20 \mathrm{mM}$ inhibitor (or vehicle) and $5 \mu \mathrm{L}$ of the enzyme. The final concentrations of the enzymes were $6 \mathrm{nM}$ (thrombin) and $1.09 \mathrm{nM}$ (factor Xa). After 10 min incubation, $5 \mu \mathrm{L} 1.0 \mathrm{mM}$ Spectrozyme TH or $2.5 \mathrm{mM}$ Spectrozyme FXa, was rapidly added and the residual enzyme activity was measured from the initial rate of increase in A405. Relative residual enzyme activity ( $\mathrm{Y}$, activity in the presence of inhibitor to that in its absence) as a function of the concentration of inhibitor was measured.

\section{Conclusions}

This work reports the first group of small, homogenous molecules that allosterically inhibit human Lys-plasmin. In particular NSGMs 31, 32, 52 and 54 are interesting initial discoveries that provide the foundation necessary for further design of advanced molecules. Allosteric inhibition usually conveys two advantages over active site inhibitors. First, allosteric sites are generally less conserved among proteins of the same superfamily. This is expected to provide enhanced specificity of action. Second, allosteric sites in principle may afford variable control over enzyme function ( $\Delta \mathrm{Y}$ not necessarily $100 \%$ ). Such variable control of enzyme activity is critical for plasmin, which is involved in multiple pathophysiological conditions. This work demonstrates this aspect more clearly than any example known in the literature. For example, NSGMs $\mathbf{4 1}$ and $\mathbf{5 0}$ display efficacies of only about 50\% (54\% $\pm 5 \%$ and $38 \% \pm 15 \%$, respectively), which implies that even at saturation, these inhibitors induce only half maximal reduction in plasmin activity. Such controlled reduction in plasmin function can help maintain balance between hemostasis and bleeding, possibly resulting in reduced adverse consequences. Also, several NSGMs display efficacies of $\sim 70 \%$ (e.g., 30, 37, 49, 52, and 54), while others (e.g., 32, 42-47) display nearly $100 \%$ inhibition (Table 1). The only other NSGM-related work described in the literature pertains to the monosulfated benzofuran class of molecules by Sidhu et al. that presents one molecule with efficacy of less than 50\% [34]. Thus, plasmin appears to present a system to rigorously test the concept of controlled allosteric regulation as an avenue for avoiding adverse consequences.

A significant number of sulfated NSGMs being reported here are new and have not been studied earlier. The NSGMs display moderate potency with $I C_{50}$ values of $45-75 \mu \mathrm{M}$ and represent promising "hits" that can be expected to guide future efforts. Despite the moderate potency, the promise of advancing the field of selective allosteric inhibitors of plasmin is good because of prior work in the area of allosteric inhibitors of thrombin, a related coagulation enzyme [34,35,44]. In this case, a rational design process transformed the initial moderate activity to sub-micromolar activity in few steps. In fact, 
we predict that coupling one more monomers to these initial dimeric "hits" will improve the inhibition profile greatly. Additionally, the NSGMs discovered here may also serve as chemical biology tools to help understand biochemical and pharmacological facets of plasmin function.

Tranexamic acid and $\varepsilon$-aminocaproic acid are the only plasmin modulators in the clinical use. Despite their success in reducing blood loss associated with major surgeries, the two antifibrinolytics suffer from severe lack of efficacy $[1,3,4]$. Specificity is also a concern as these lysine analogs may recognize a negatively charged domain(s) on non-target protein(s). An example of this is seizure attacks in some patients. Aprotinin, a plasmin inhibitor in limited use in some countries, also suffers from a lack of specificity $[1,5,6]$. Several plasmin inhibitors being developed as antifibrinolytics include KDI-L17R [15] textilinin-1 [16] and cyclic peptidomimetics $[13,14]$. Yet, these are active site inhibitors and their selectivity for plasmin is challenging because of the similarity of active site geometries of a number of trypsin-like proteases. Allosteric inhibitors being presented in this work should provide a fundamentally new route to plasmin inhibition. Toward this end, a putative binding site for NSGMs on the catalytic domain of plasmin was earlier proposed using a computational approach. The putative heparin-binding site includes Arg637, Arg644, Lys645, Lys651, Arg776, and Arg779 in addition to other hydrophobic amino acids. Specifically, this binding site was claimed to be a plausible binding site for the highly sulfated low molecular weight lignins [27], and hence, it could be exploited in rational design of more potent allosteric inhibitors of plasmin.

Overall, the discovery of inhibitors $\mathbf{3 1}, \mathbf{3 2}, \mathbf{5 2}$ and $\mathbf{5 4}$ presents a proof-of-concept that homogeneous sulfated NSGMs afford allosteric inhibition of human Lys-plasmin. These small sulfated NSGMs offer many advantages including i) adequate aqueous solubility ( $>25 \mathrm{mg} / \mathrm{mL})$, which is expected to help antifibrinolytic use during surgeries, ii) limited cellular and central nervous system toxicity arising from their highly charged nature, iii) reasonable chemical stability, particularly under neutral and basic conditions [45], and iv) ease of chemical synthesis [41,46,47]. Further efforts are necessary to develop these sulfated NSGMs into clinically relevant molecules.

\section{Supplementary Materials}

Experimental parts including synthetic and identification protocols, synthetic schemes, and characterization data $\left({ }^{1} \mathrm{H}\right.$ - and ${ }^{13} \mathrm{C}-\mathrm{NMR}$, and MS/ESI) of new molecules are provided in supplementary information. Details of procedures and equations of inhibition studies as well as Michaelis-Menten kinetics are also provided. This material is available free of charge via the online version of the paper. Supplementary materials can be accessed at: http://www.mdpi.com/1420-3049/20/01/0608/s1.

\section{Acknowledgments}

This work was supported by the VCU Postdoctoral Research Grant to RAAH from Virginia Commonwealth University and grant HL107152 from the National Institutes of Health to URD.

\section{Author Contributions}

RK and DTW synthesized new members of the library; RAAH performed screening and biochemical studies; RAAH and URD wrote the manuscript. Each author has given approval to the final version of the manuscript. 


\section{Conflicts of Interest}

The authors declare no conflict of interest.

\section{References}

1. Al-Horani, R.A.; Desai, U.R. Recent Advances on plasmin inhibitors for the treatment of fibrinolysis-related disorders. Med. Res. Rev. 2014, 34, 1168-1216.

2. Swedberg, J.E.; Harris, J.M. Natural and engineered plasmin inhibitors: Applications and design strategies. Chembiochem 2012, 13, 336-348.

3. Royston, D. Blood-sparing drugs: Aprotinin, tranexamic acid, and epsilon-aminocaproic acid. Int. Anesthesiol. Clin. 1995, 33,155-179.

4. Makhija, N.; Sarupria, A.; Kumar Choudhary, S.; Das, S.; Lakshmy, R.; Kiran, U. Comparison of epsilon aminocaproic acid and tranexamic acid in thoracic aortic surgery: Clinical efficacy and safety. J. Cardiothorac. Vasc. Anesth. 2013, 27, 1201-1207.

5. Mangano, D.T.; Tudor, I.C.; Dietzel, C. The risk associated with aprotinin in cardiac surgery. N. Engl. J. Med. 2006, 354, 353-365.

6. Schneeweiss, S.; Seeger, J.D.; Landon, J.; Walker, A.M. Aprotinin during coronary-artery bypass grafting and risk of death. N. Engl. J. Med. 2008, 358, 771-783.

7. Lecker, I.; Wang, D.S.; Romaschin, A.D.; Peterson, M.; Mazer, C.D.; Orser, B.A. Tranexamic acid concentrations associated with human seizures inhibit glycine receptors. J. Clin. Investig. 2012, 122, 4654-4666.

8. Dhir, A. Antifibrinolytics in cardiac surgery. Ann. Card. Anaesth. 2013, 16, 117-125.

9. Perona, J.J.; Craik, C.S. Structural basis of substrate specificity in the serine proteases. Protein Sci. 1995, 4, 337-360.

10. Sanders, T.C.; Seto, C.T. 4-Heterocyclohexanone-based inhibitors of the serine protease plasmin. J. Med. Chem. 1999, 42, 2969-2976.

11. Xue, F.; Seto, C.T. Selective inhibitors of the serine protease plasmin: Probing the S3 and S3' subsites using a combinatorial library. J. Med. Chem. 2005, 48, 6908-6917.

12. Xue, F.; Seto, C.T. Structure-activity studies of cyclic ketone inhibitors of the serine protease plasmin: Design, synthesis, and biological activity. Bioorg. Med. Chem. 2006, 14, 8467-8487.

13. Saupe, S.M.; Leubner, S.; Betz, M.; Klebe, G.; Steinmetzer, T. Development of new cyclic plasmin inhibitors with excellent potency and selectivity. J. Med. Chem. 2013, 56, 820-831.

14. Saupe, S.M.; Steinmetzer, T. A new strategy for the development of highly potent and selective plasmin inhibitors. J. Med. Chem. 2012, 55, 1171-1180.

15. Bajaj, M.S.; Ogueli, G.I.; Kumar, Y.; Vadivel, K.; Lawson, G.; Shanker, S.; Schmidt, A.E.; Bajaj, S.P. Engineering kunitz domain 1 (KD1) of human tissue factor pathway inhibitor-2 to selectively inhibit fibrinolysis: properties of KD1-L17R variant. J. Biol. Chem. 2011, 286, 4329-4340.

16. Flight, S.M.; Johnson, L.A.; Du, Q.S.; Warner, R.L.; Trabi, M.; Gaffney, P.J.; Lavin, M.F.; de Jersey, J.; Masci, P.P. Textilinin-1, an alternative anti-bleeding agent to aprotinin: Importance of plasmin inhibition in controlling blood loss. Br. J. Haematol. 2009, 145, 207-211. 
17. Devy, L.; Rabbani, S.A.; Stochl, M.; Ruskowski, M.; Mackie, I.; Naa, L.; Toews, M.; van Gool, R.; Chen, J.; Ley, A.; et al. PEGylated DX-1000: Pharmaco-kinetics and antineoplastic activity of a specific plasmin inhibitor. Neoplasia 2007, 9, 927-937.

18. Swedberg, J.E.; Harris, J.M. Plasmin substrate binding site cooperativity guides the design of potent peptide aldehyde inhi-bitors. Biochemistry 2011, 50, 8454-8462.

19. Teno, N.; Gohda, K.; Wanaka, K.; Sueda, T.; Tsuda, Y. Identi-fication of novel plasmin inhibitors possessing nitrile moiety as warhead. Bioorg. Med. Chem. Lett. 2011, 21, 6305-6309.

20. Cheng, L.; Pettersen, D.; Ohlsson, B.; Schell, P.; Karle, M.; Evertsson, E.; Pahlén, S.; Jonforsen, M.; Plowright, A.T.; Boström, J.; et al. Discovery of the fibrinolysis inhibitor AZD6564, acting via interference of a protein-protein interaction. ACS Med. Chem. Lett. 2014, 5, 538-543.

21. Boström, J.; Grant, J.A.; Fjellström, O.; Thelin, A.; Gustafsson, D. Potent fibrinolysis inhibitor discovered by shape and electrostatic complementarity to the drug tranexamic acid. J. Med. Chem. 2013, 56, 3273-3280.

22. Smith, G.F.; Sundboom, J.L. Heparin and protease inhibition. II. The role of heparin in the ATIII inactivation of thrombin, plasmin, and trypsin. Thromb. Res. 1981, 22, 115-133.

23. Jordan, R.E.; Oosta, G.M.; Gardner, W.T.; Rosenberg, R.D. The binding of low molecular weight heparin to hemostatic enzymes. J. Biol. Chem. 1980, 255, 10073-10080.

24. Yomtova, V.M.; Stambolieva, N.A.; Blagoev, B.M. Kinetic study of the effect of heparin on the amidase activity of trypsin, plasmin and urokinase. Thromb. Haemost. 1983, 49, 199-203.

25. Bauer, P.I.; Pozsgay, M.; Machovich, R.; Elödi, P.; Horváth, I. The interaction of heparin with human plasmin. Int. J. Biochem. 1983, 15, 871-874.

26. Legras, S.; Diczhazi, C.; Moczar, M. $N$-oleoyl heparin inhibits the amidolytic activity of plasmin and urokinase. Int. J. Biol. Macromol. 1992, 14, 97-99.

27. Henry, B.L.; Abdel Aziz, M.H.; Zhou, Q.; Desai, U.R. Sulfated, low-molecular-weight lignins are potent inhibitorsof plasmin, in addition to thrombin and factor Xa: Novel opportunity for con-trolling complex pathologies. Thromb. Haemost. 2010, 103, 507-515.

28. Ledoux, D.; Papy-Garcia, D.; Escartin, Q.; Sagot, M.A.; Cao, Y.; Barritault, D.; Courtois, J.; Hornebeck, W.; Caruelle, J.P. Human plasmin enzymatic activity is inhibited by chemically modified dextrans. J. Biol. Chem. 2000, 275, 29383-29390.

29. Vörös, G.; Kolev, K.; Csomor, K.; Machovich, R. Inhibition of plasmin activity by sulfated polyvinylalcohol-acrylate copolymers. Thromb. Res. 2000, 100, 353-361.

30. Raman, K.; Karuturi, R.; Swarup, V.P.; Desai, U.R.; Kuberan, B. Discovery of novel sulfonated small molecules that inhibit vascular tube formation. Bioorg. Med. Chem. Lett. 2012, 22, 4467-4470.

31. Gunnarsson, G.T.; Desai, U.R. Designing small, nonsugar activators of antithrombin using hydropathic interaction analyses. J. Med. Chem. 2002, 45, 1233-1243.

32. Gunnarsson, G.T.; Desai, U.R. Exploring new non-sugar sulfated molecules as activators of antithrombin. Bioorg. Med. Chem. Lett. 2003, 13, 679-683.

33. Patel, N.J.; Karuturi, R.; Al-Horani, R.A.; Baranwal, S.; Patel, J.; Desai, U.R.; Patel, B.B. Synthetic, non-saccharide, glycosaminoglycan mimetics selectively target colon cancer stem cells. ACS Chem. Biol. 2014, 9, 1826-1833.

34. Sidhu, P.S.; Liang, A.; Mehta, A.Y.; Abdel Aziz, M.H.; Zhou, Q.; Desai, U.R. Rational design of potent, small, synthetic allosteric inhibitors of thrombin. J. Med. Chem. 2011, 54, 5522-5531. 
35. Abdel Aziz, M.H.; Sidhu, P.S.; Liang, A.; Kim, J.Y.; Mosier, P.D.; Zhou, Q.; Farrell, D.H.; Desai, U.R. Designing allosteric regulators of thrombin. Monosulfated benzofuran dimers selectively interact with Arg173 of exosite 2 to induce inhibition. J. Med. Chem. 2012, 55, 6888-6897.

36. Al-Horani, R.A.; Liang, A.; Desai, U.R. Designing nonsaccharide, allosteric activators of antithrombin for accelerated inhibition of factor Xa. J. Med. Chem. 2011, 54, 6125-6138.

37. Karuturi, R.; Al-Horani, R.A.; Mehta, S.C.; Gailani, D.; Desai, U.R. Discovery of allosteric modulators of factor XIa by targeting hydrophobic domains adjacent to its heparin-binding site. J. Med. Chem. 2013, 56, 2415-2428.

38. Al-Horani, R.A.; Ponnusamy, P.; Mehta, A.Y.; Gailani, D.; Desai, U.R. Sulfated pentagalloylglucoside is a potent, allosteric, and selective inhibitor of factor XIa. J. Med. Chem. 2013, 56, 867-878.

39. Al-Horani, R.A.; Desai, U.R. Designing allosteric inhibitors of factor XIa. Lessons from the interactions of sulfated pentagalloylglucopyranosides. J. Med. Chem. 2014, 57, 4805-4818.

40. Desai, B.J.; Boothello, R.S.; Mehta, A.Y.; Scarsdale, J.N.; Wright, H.T.; Desai, U.R. Interaction of thrombin with sucrose octasulfate. Biochemistry 2011, 50, 6973-6982.

41. Al-Horani, R.A.; Karuturi, R.; Verespy Ш, S.; Desai, U.R. Synthesis of glycosaminoglycan mimetics through sulfation of polyphenols. Methods Mol. Biol. 2015, 1229, 49-67.

42. Al-Horani, R.A.; Desai, U.R. Chemical sulfation of small molecules-Advances and challenges. Tetrahedron 2010, 66, 2907-2918.

43. Al-Horani, R.A.; Mehta, A.Y.; Desai, U.R. Potent direct inhibitors of factor Xa based on the tetrahydroisoquinoline scaffold. Eur. J. Med. Chem. 2012, 54, 771-783.

44. Sidhu, P.S.; Abdel Aziz, M.H.; Sarkar, A.; Mehta, A.Y.; Zhou, Q.; Desai, U.R. Designing allosteric regulators of thrombin. Exosite 2 features multiple subsites that can be targeted by sulfated small molecules for inducing inhibition. J. Med. Chem. 2013, 56, 5059-5070.

45. Liang, A.; Thakkar, J.N.; Desai, U.R. Study of physico-chemical properties of novel highly sulfated, aromatic, mimetics of heparin and heparan sulfate. J. Pharm Sci. 2010, 99, 1207-1216.

46. Desai, U.R. The promise of sulfated synthetic small molecules as modulators of glycosaminoglycan function. Future Med. Chem. 2013, 5, 1363-1366.

47. Correia-da-Silva, M.; Sousa, E.; Pinto, M.M. Emerging sulfated flavonoids and other polyphenols as drugs: Nature as an inspiration. Med. Res. Rev. 2014, 34, 223-279.

Sample Availability: Samples of compounds are available from the authors.

(C) 2015 by the authors; licensee MDPI, Basel, Switzerland. This article is an open access article distributed under the terms and conditions of the Creative Commons Attribution license (http://creativecommons.org/licenses/by/4.0/). 